\title{
Hyperbranched Polymer through Initiator-Fragment Incorporation Radical Copolymerization of Divinyl Adipate with Allyl Acetate: Synthesis, Characterization, Dye Solubilization, Metal-Nanoparticle Stabilization, and Porous Film Formation
}

\author{
Tsuneyuki Sato ${ }^{\dagger}$ Kazuki Nomura, Tomohiro Hirano, and Makiko Seno \\ Department of Chemical Science and Technology, Faculty of Engineering, Tokushima University, \\ 2-1 Minamijosanjima, Tokushima 770-8506, Japan
}

(Received September 2, 2005; Accepted October 22, 2005; Published March 15, 2006)

\begin{abstract}
The copolymerization of divinyl adipate (DVA) as an effective cross-linker with allyl acetate (AAc) as a degradative chain transfer reagent was carried out at 70 and $80^{\circ} \mathrm{C}$ in benzene using dimethyl $2,2^{\prime}$-azobisisobutyrate (MAIB) of high concentrations as initiator. When the MAIB concentration as high as $0.60 \mathrm{~mol} / \mathrm{L}$ was used, the copolymerization of DVA $(0.20 \mathrm{~mol} / \mathrm{L})$ and AAc $(0.50 \mathrm{~mol} / \mathrm{L})$ proceeded homogeneously without any gelation to give soluble copolymers in a yield of about $30 \%$ based on the total weight of DVA, AAc, and MAIB. The copolymer formed in the copolymerization at $80^{\circ} \mathrm{C}$ for $6 \mathrm{~h}$ consisted of the DVA units with $(3 \mathrm{~mol} \%)$ and without $(24 \mathrm{~mol} \%)$ double bond, the AAc unit $(35 \mathrm{~mol} \%)$, and the methoxycarbonylpropyl group (38 mol \%) from MAIB. Such a large fraction of the incorporated initiator-fragment as terminal group indicates that the copolymer has a hyperbranched structure. The copolymer showed an upper critical solution temperature $\left(38^{\circ} \mathrm{C}\right.$ on cooling) in a tetrahydrofuran (THF)-water $[2: 1(\mathrm{v} / \mathrm{v})]$ mixture, and also exhibited potentials in solubilization of Rhodamine $6 \mathrm{G}$ as a dye probe and stabilization of metal nanoparticles. A porous film was obtained simply by casting a copolymer solution in THF.

[DOI 10.1295/polymj.38.240]

KEY WORDS Radical Copolymerization / Hyperbranched Polymer / Divinyl Monomer / Dye Solubilization / Metal Nanoparticle Stabilization / Porous Film /
\end{abstract}

Recently dendritic polymers such as dendrimers and hyperbranched polymers have attracted much attention because of their unique structures and properties, for example, globular and void-containing shape, a great number of terminal groups, no crystallization, and low solution viscosity. ${ }^{1-8}$ In the preceding papers we have developed the initiator-fragment incorporation radical polymerization (IFIRP) as a convenient method for one-pot synthesis of soluble hyperbranched polymers. ${ }^{9-14}$ The radical polymerization including a divinyl monomer is well known to yield insoluble cross-linked polymer, of which the molecular weight is usually treated to be extremely large or infinite. However, when much higher initiator concentration is used in the polymerization of divinyl monomer, the molecular weight of the resulting polymer is so decreased and hence the polymer becomes soluble and is of hyperbranched structure. A large number of initiator fragments are then incorporated as terminal groups into the polymer via initiation and primary termination, leading to naming of IFIRP. The decrease in the polymer molecular weight can be enhanced by the presence of a retarder or a chain transfer reagent. ${ }^{9,15,16}$

On the other hand, allyl monomers usually give oligomers only in a low yield by usual radical poly- merzation because of degradative chain transfer reaction to the monomers. ${ }^{17,18}$ However, allyl acetate (AAc) as an allyl monomer shows a considerably high reactivity in the radical copolymerization with vinyl acetate (VAc) as a non-conjugative monomer. ${ }^{19}$ These facts led us to extend the IFIRP to the copolymerization system of AAc and divinyl adipate (DVA).

The present paper describes the results of copolymerization of DVA and AAc with dimethyl 2,2'-azobisisobutyrate (MAIB) of high concentrations as initiator and characterization of the resulting copolymer. The copolymer showed potentials in dye-solubilization, metal nanoparticle-stabilization, and porous film formation.

\section{EXPERIMENTAL}

\section{Materials}

Commercially available DVA and AAc were used after distillation. MAIB (supplied by Otsuka Chemical Co., Ltd.) was recrystallized from methanol. Benzene was treated with sulfuric acid and distilled. Other solvents were used after distillation. $\mathrm{H}\left(\mathrm{AuCl}_{4}\right) \cdot 4 \mathrm{H}_{2} \mathrm{O}$, $\mathrm{AgNO}_{3}, \mathrm{Pd}\left(\mathrm{CH}_{3} \mathrm{COO}\right)_{2}$, and $\mathrm{NaBH}_{4}$ were used as received.

${ }^{\dagger}$ To whom correspondence should be addressed (Tel: +81-88-656-7402, Fax: +81-88-655-7025, E-mail: sato@ chem.tokushima-u.ac.jp). 


\section{Polymerization}

Copolymerization of DVA and AAc with MAIB was carried out in a degassed and sealed glass tube at a given temperature. The resulting copolymer was isolated by pouring the polymerization mixture into a large excess of $n$-hexane. The conversions of the vinyl groups of DVA and AAc were followed in situ as a function of time by Fourier transform near-infrared (FT-NIR) spectroscopy, where the copolymerization was performed in a degassed and sealed Pyrex glass tube ( $5 \mathrm{~mm}$ diameter) in a custom-made aluminum furnace with an FT-NIR measurement system. ${ }^{20}$

\section{Preparation of Copolymer-Stabilized Metal Particles}

A $\mathrm{H}\left(\mathrm{AuCl}_{4}\right) \cdot 4 \mathrm{H}_{2} \mathrm{O}(2.1 \mathrm{mg}, 5.1 \mu \mathrm{mol})$ solution in tetrahydrofuran (THF) $(0.5 \mathrm{~mL})$ was added to a copolymer $(100 \mathrm{mg})$ solution in THF $(5 \mathrm{~mL})$ and stirred at room temperature for $0.5 \mathrm{~h}$. To this solution, a $\mathrm{NaBH}_{4}(0.96 \mathrm{mg}, 25.4 \mu \mathrm{mol})$ solution in methanol $(0.5$ $\mathrm{mL}$ ) was added and stirred at room temperature for $3 \mathrm{~h}$. The resulting reddish purple reaction mixture was concentrated and poured into a large excess of $n$-hexane. The precipitated Au-containing polymer was isolated and dried under a vacuum. $\mathrm{A}_{\mathrm{AgNO}_{3}}(0.79 \mathrm{mg}, 4.6$ $\mu \mathrm{mol})$ solution in methanol $(0.5 \mathrm{~mL})$ was added to a copolymer $(50 \mathrm{mg})$ solution in THF $(5 \mathrm{~mL})$ and stirred for $0.5 \mathrm{~h}$. To the solution, a $\mathrm{NaBH}_{4}(0.087 \mathrm{mg}, 2.3$ $\mu \mathrm{mol})$ in methanol $(0.5 \mathrm{~mL})$ was added and stirred for $1 \mathrm{~h}$. The resulting yellowish brown solution was concentrated and poured into a large excess of $n$-hexane. The precipitated Ag-containing copolymer was isolated and dried under a vacuum. $\mathrm{A} \mathrm{Pd}\left(\mathrm{CH}_{3} \mathrm{COO}\right)_{2}(2.11$ $\mathrm{mg}, 9.4 \mu \mathrm{mol})$ solution in THF $(0.5 \mathrm{~mL})$ was added to a copolymer $(100 \mathrm{mg})$ solution in THF $(5 \mathrm{~mL})$ and stirred for $0.5 \mathrm{~h}$. To the solution, a $\mathrm{NaBH}_{4}(1.78 \mathrm{mg}$, $47 \mu \mathrm{mol})$ solution in methanol $(0.5 \mathrm{~mL})$ was added and stirred for $1 \mathrm{~h}$. The resulting brown solution was concentrated and poured into a large excess of $n$-hexane. The precipitated Pd-containing copolymer was isolated and dried under a vacuum.

\section{Measurements}

The conversions of the vinyl groups of the comonomers were monitored by the absorbances near 6190 $\mathrm{cm}^{-1}$ (DVA) and $6130 \mathrm{~cm}^{-1}$ (AAc), being assignable to the overtone stretching vibrations of $=\mathrm{C}-\mathrm{H}$ bonds in the vinyl groups, using a Jasco INT-400 spectrometer equipped with a mercury-cadmium-telluride detector. ${ }^{1} \mathrm{H}$ NMR spectra were obtained with a Jeol OX spectrometer $(400 \mathrm{MHz})$. Gel permeation chromatography (GPC) was performed at $40{ }^{\circ} \mathrm{C}$ using a Tosoh HLC-8220 GPC chromatograph (columns; TSK-Gel Super HZM $\times 2$, [polymer] $=1 \mathrm{mg} / \mathrm{mL}$, flow rate $=$ $0.35 \mathrm{~mL} / \mathrm{min}$ ) with THF as eluent. From the GPC results, number-average $\left(M_{\mathrm{n}}\right)$ and weight-average $\left(M_{\mathrm{w}}\right)$ molecular weights were estimated with polystyrene standards calibration. The optical transmittance of a copolymer solution was monitored at $500 \mathrm{~nm}$ as a function of temperature with a Jasco V-550 spectrometer with a heating rate of $0.5^{\circ} \mathrm{C} / \mathrm{min}$. The UV-vis spectra were also measured with a Jasco V-550 spectrometer. The viscosity of copolymer solutions in benzene was measured with a Ubbelohde viscometer at $25^{\circ} \mathrm{C}$. Dynamic thermogravimetry (TG) of the copolymer was performed under a nitrogen atmosphere (flow rate $=20 \mathrm{~mL} / \mathrm{min}$ ) with a Shimadzu TGA-50 thermogravimeter at a heating rate of $10^{\circ} \mathrm{C} / \mathrm{min}$. A differential scanning calorimetric (DSC) curve was obtained with a Shimadzu DSC (under $\mathrm{N}_{2}$, heating rate $\left.=10^{\circ} \mathrm{C} / \mathrm{min}\right)$. Optical microscope imaging of the cast copolymer film was done with an Olympus BX50 microscope. Confocal scanning laser microscopic measurements were performed with a LEXT OLS3000 Olympus microscope with a laser operating at $408 \mathrm{~nm}$. Transmission electron microscopic (TEM) observation was conducted by Sanyo Chemical Industries, Ltd. with a Hitachi-7100 electron microscope at an accelerating voltage of $100 \mathrm{kV}$. The specimen for the copolymer was prepared by immersing a carboncoated copper grid into a $0.1 \mathrm{wt} \%$ copolymer solution in THF which was dried under vacuum and stained with ruthenium dioxide. Those for the metalcontaining copolymers were similarly done by using $0.01 \mathrm{wt} \%$ copolymer solutions in benzene without staining.

\section{RESULTS AND DISCUSSION}

\section{Copolymerization of DVA and AAc with MAIB in Ben- zene}

The copolymerization of DVA with AAc was conducted at 70 and $80^{\circ} \mathrm{C}$ in benzene using MAIB as initiator at high concentrations $(0.50-0.70 \mathrm{~mol} / \mathrm{L})$. The results obtained are summarized in Table I.

At first, the polymerization was examined at $80^{\circ} \mathrm{C}$. When the concentration of DVA as a divinyl monomer was changed fixing the concentrations of AAc and MAIB at $0.50 \mathrm{~mol} / \mathrm{L}$ (runs $1-7$ ), the polymerization at the low DVA concentrations of 0.10 and 0.15 $\mathrm{mol} / \mathrm{L}$ (runs 6 and 7) proceeded homogeneously without any gelation, while the use of the higher DVA concentrations $(0.20-0.50 \mathrm{~mol} / \mathrm{L})$ resulted in gelation (runs 1-5). When the MAIB concentration was varied fixing the concentrations of DVA and AAc at 0.20 and $0.50 \mathrm{~mol} / \mathrm{L}$, respectively, (runs 5, 8 and 9), the polymerization at the higher initiator concentrations $(0.60$ and $0.70 \mathrm{~mol} / \mathrm{L}$ ) proceeded with no gelation, but gelation occurred at a lower MAIB concentration of 0.50 $\mathrm{mol} / \mathrm{L}$. When the AAc concentration was changed at the fixed concentrations of DVA $(0.20 \mathrm{~mol} / \mathrm{L})$ and 
Table I. Copolymerization of DVA and AAc with MAIB in benzene

\begin{tabular}{ccccccccc}
\hline Run & $\begin{array}{c}{[\mathrm{DVA}]} \\
(\mathrm{mol} / \mathrm{L})\end{array}$ & $\begin{array}{c}{[\mathrm{AAc}]} \\
(\mathrm{mol} / \mathrm{L})\end{array}$ & $\begin{array}{c}{[\mathrm{MAIB}]} \\
(\mathrm{mol} / \mathrm{L})\end{array}$ & $\begin{array}{c}\text { Temp. } \\
\left({ }^{\circ} \mathrm{C}\right)\end{array}$ & $\begin{array}{c}\text { Time } \\
(\mathrm{h})\end{array}$ & $\begin{array}{c}\text { Yield } \\
(\%)\end{array}$ & $\begin{array}{c}M_{\mathrm{n}} \\
\left(\times 10^{-3}\right)\end{array}$ & $M_{\mathrm{w}} / M_{\mathrm{n}}$ \\
\hline $1^{\mathrm{a}}$ & 0.50 & 0.50 & 0.50 & 80 & 4 & 66 & & \\
$2^{\mathrm{a}}$ & 0.40 & 0.50 & 0.50 & 80 & 4 & 76 & & \\
$3^{\mathrm{a}}$ & 0.35 & 0.50 & 0.50 & 80 & 4 & 66 & & \\
$4^{\mathrm{a}}$ & 0.30 & 0.50 & 0.50 & 80 & 4 & 45 & & \\
$5^{\mathrm{a}}$ & 0.20 & 0.50 & 0.50 & 80 & 4 & 33 & & \\
6 & 0.15 & 0.50 & 0.50 & 80 & 4 & 26 & 4.6 & 1.7 \\
7 & 0.10 & 0.50 & 0.50 & 80 & 4 & 16 & 3.9 & 1.4 \\
8 & 0.20 & 0.50 & 0.60 & 80 & 4 & 28 & 8.1 & 1.9 \\
9 & 0.20 & 0.50 & 0.70 & 80 & 4 & 30 & 5.8 & 2.1 \\
$10^{\mathrm{a}}$ & 0.20 & 0.40 & 0.60 & 80 & 4 & 32 & & \\
$11^{\mathrm{a}}$ & 0.20 & 0.30 & 0.60 & 80 & 4 & 29 & & \\
12 & 0.20 & 0.50 & 0.60 & 80 & 0.5 & 12 & 5.4 & 1.6 \\
13 & 0.20 & 0.50 & 0.60 & 80 & 1 & 19 & 6.5 & 1.7 \\
14 & 0.20 & 0.50 & 0.60 & 80 & 2 & 24 & 6.8 & 1.8 \\
15 & 0.20 & 0.50 & 0.60 & 80 & 6 & 31 & 8.3 & 1.9 \\
16 & 0.20 & 0.50 & 0.60 & 80 & 8 & 32 & 8.2 & 2.0 \\
17 & 0.20 & 0.50 & 0.60 & 70 & 1 & 16 & 6.8 & 1.7 \\
18 & 0.20 & 0.50 & 0.60 & 70 & 3 & 27 & 7.9 & 2.0 \\
19 & 0.20 & 0.50 & 0.60 & 70 & 6 & 33 & 8.7 & 2.2 \\
20 & 0.20 & 0.50 & 0.60 & 70 & 9 & 34 & 9.0 & 2.2 \\
21 & 0.20 & 0.50 & 0.60 & 70 & 12 & 33 & 9.2 & 2.3 \\
\hline
\end{tabular}

${ }^{\mathrm{a}}$ Gelation was observed.

MAIB $(0.60 \mathrm{~mol} / \mathrm{L})$ (runs 8,10 and 11$)$, the use of the lower AAc concentrations of 0.30 and $0.40 \mathrm{~mol} / \mathrm{L}$ caused gelation, while no gelation was observed in the polymerization at the higher AAc concentration of $0.50 \mathrm{~mol} / \mathrm{L}$. Thus, the use of higher concentrations of MAIB as initiator and AAc as chain transfer reagent and the lower concentration of DVA as divinyl monomer is favorable for formation of soluble copolymer without gelation in the present polymerization. The copolymer yield in the polymerization at $80^{\circ} \mathrm{C}$ for $4 \mathrm{~h}$ increased with increasing DVA concentration and was rather insensitive to the concentrations of AAc and MAIB. The copolymer yield was estimated based on the total weight of DVA, AAc, and MAIB, considering $N_{2}$-elimination on the decomposition of MAIB.

A detail examination was performed on the homogeneous copolymerization at 70 and $80^{\circ} \mathrm{C}$, where the concentrations of DVA, AAc, and MAIB were $0.20,0.50$, and $0.60 \mathrm{~mol} / \mathrm{L}$, respectively. As shown as runs 8 and 12-21 in Table I, the copolymer yield increased with time and leveled off to about $30 \%$ over $4 \mathrm{~h}$ at $80^{\circ} \mathrm{C}$, and to about $33 \%$ over $6 \mathrm{~h}$ at $70^{\circ} \mathrm{C}$. The molecular weight and the molecular weight distribution $\left(M_{\mathrm{w}} / M_{\mathrm{n}}\right)$ of the copolymer tended to increase with copolymer yield.

Separately the conversions of the vinyl groups of DVA and AAc were in situ monitored by FT-NIR. Figure 1a shows NIR spectra of the copolymerization system at $80^{\circ} \mathrm{C}$ in dioaxne at 0 and $300 \mathrm{~min}$, where the concentrations of DVA, AAc, and MAIB were
$0.20,0.50$, and $0.60 \mathrm{~mol} / \mathrm{L}$, respectively. The absorption at $6190 \mathrm{~cm}^{-1}$ is due to the double bonds of DVA and the one at $6130 \mathrm{~cm}^{-1}$ due to that of AAc. From these absorption areas, the conversions of DVA and AAc were estimated as a function of time as shown in Figure 1b. The conversion of vinyl groups of DVB increased rapidly with time in the early stage and then slowly up to $95 \%$ at $5 \mathrm{~h}$. The vinyl group of AAc was consumed more slowly than those of DVB. The conversion of the AAc reached $75 \%$ at $5 \mathrm{~h}$. Thus, the conversions of both comonomers almost leveled off over $4 \mathrm{~h}$, well corresponding to the leveling phenomenon above described for the copolymer yield. The somewhat higher reactivity of DVB compared to AAc observed here is conformable to the monomer reactivity ratios $\left(r_{1}=0.45\right.$ and $\left.r_{2}=0.60\right)$ reported for the copolymerization of AAc $\left(\mathrm{M}_{1}\right)$ and $\operatorname{VAc}\left(\mathrm{M}_{2}\right)$ at $60{ }^{\circ} \mathrm{C}^{19}$ On the other hand, as shown in Table I, the copolymer yield (30\%) based on the total weight of the comonomers and initiator was very low although the conversions of the comonomers were considerably high. This is because of the inefficient use of the initiator and probably because of the formation of low molecular weight products which were soluble in $n$-hexane containing a small amount of benzene (the polymerization solvent).

\section{Characterization of the Resulting Copolymer}

The solubility of the resulting copolymer was checked, where the examined copolymer was obtained 
(a)

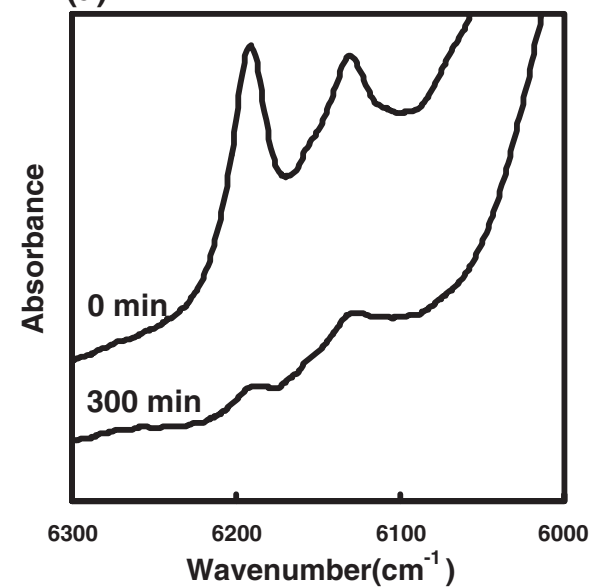

(b)

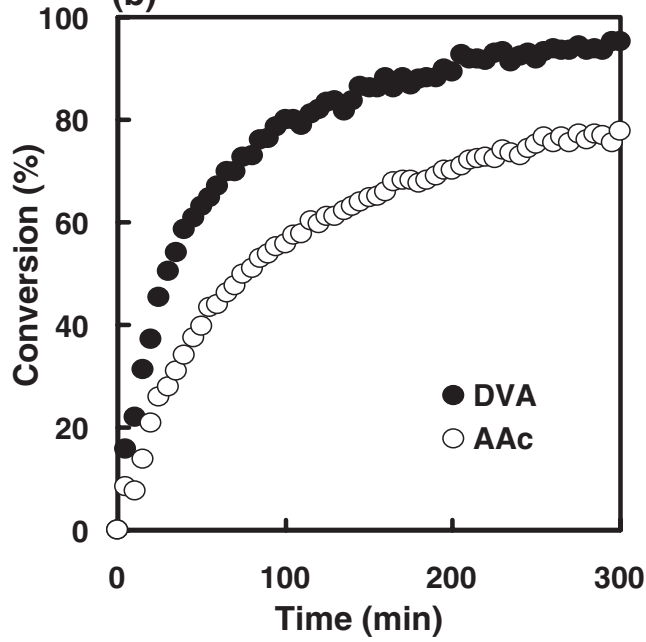

Figure 1. (a) NIR spectra of the copolymerization system and (b) time-conversion curves of DVA and AAc observed in the copolymerization of DVA and AAc with MAIB in dioxane at $80^{\circ} \mathrm{C} . \quad[\mathrm{DVA}]=0.20 \mathrm{~mol} / \mathrm{L}, \quad[\mathrm{AAc}]=0.50 \mathrm{~mol} / \mathrm{L}, \quad[\mathrm{MAIB}]=$ $0.60 \mathrm{~mol} / \mathrm{L}$.

in the copolymerization of DVA $(0.20 \mathrm{~mol} / \mathrm{L})$ and AAc $(0.50 \mathrm{~mol} / \mathrm{L})$ with MAIB $(0.60 \mathrm{~mol} / \mathrm{L})$ at $80^{\circ} \mathrm{C}$ in benzene for $4 \mathrm{~h}$ (run 8 in Table I). Good solvents were benzene, toluene, THF, chloroform, acetone, acetonitrile, $N, N$-dimethylformamide, and dimethyl sulfoxide, while non-solvents were $n$-hexane, cyclohexane, methanol, ethanol, and water.

Some hyperbranched polymers showed an upper critical solution temperature (UCST) in a waterorganic solvent mixture, indicating that they are thermally sensitive. ${ }^{11,13,14}$ Much suppressed interactions between hyperbranched polymer molecules are expected to cause the sharp behaviors on dissolution and precipitation. The copolymer obtained in run 8 in Table I also exhibited UCST in a THF-water [2:1 $(\mathrm{v} / \mathrm{v})]$ mixture. Figure 2 illustrates the temperature effect on the transmittance of a copolymer solution $[0.33 \%(\mathrm{wt} / \mathrm{v})]$ on cooling and heating. A considerably large hysteresis was observed. Such thermal hys-

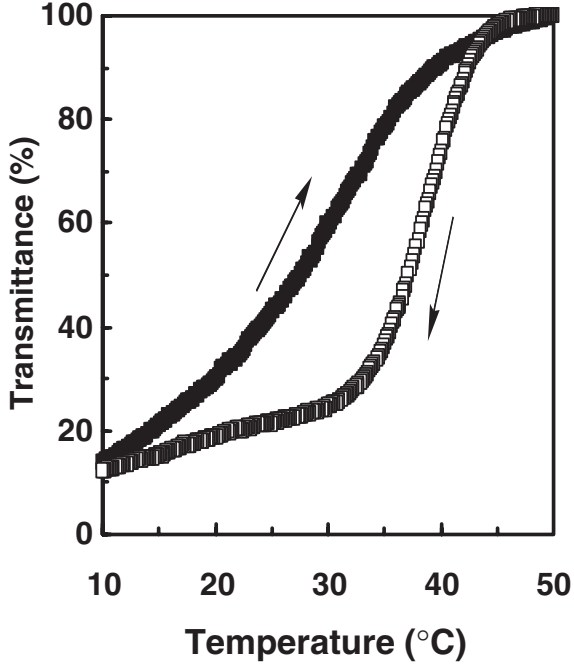

Figure 2. Temperature effect on the transmittance of a copolymer solution $[0.33 \%(\mathrm{wt} / \mathrm{v})]$ in a THF-water $[2: 1(\mathrm{v} / \mathrm{v})]$ mixture on cooling $(\leftarrow)$ and heating $(\rightarrow)$. The copolymer was prepared by the copolymerization of DVA $(0.20 \mathrm{~mol} / \mathrm{L})$ and AAc $(0.50 \mathrm{~mol} / \mathrm{L})$ with MAIB $(0.60 \mathrm{~mol} / \mathrm{L})$ in benzene at $80^{\circ} \mathrm{C}$ for $4 \mathrm{~h}$.

teresis is known to result from a difference in the rates of precipitation and dissolution processes. ${ }^{21}$ In most of the reported cases, ${ }^{22-25}$ the rate of dissolution process is slower than that of precipitation process. Interestingly, Figure 2 shows that the inverse phenomenon occurred for the present case. This may be ascribed to the unique hyperbranched structure of the copolymer although the true reason is obscure at present. When UCST was defined as temperature at which the transmittance became $50 \%$, the UCST was estimated to be $38^{\circ} \mathrm{C}$ on cooling and $27^{\circ} \mathrm{C}$ on heating.

Figure 3 presents ${ }^{1} \mathrm{H}$ NMR spectrum of the same copolymer formed in the copolymerization at $80^{\circ} \mathrm{C}$ for $4 \mathrm{~h}$ (run 8 in Table I). Peak assignments are denoted in the figure. Thus, the copolymer contained the DVA units with and without an intact double bond, the AAc unit, and the methoxycarbonylpropyl group as the MAIB-fragment.

The copolymer composition was estimated from the peak areas corresponding to the protons of vinyl (7.5 and $5.0 \mathrm{ppm}), O$-methine $(5.0 \mathrm{ppm}), O$-methylene $(4.0$ $\mathrm{ppm})$, and methoxycarbonyl (3.8 ppm) groups in the ${ }^{1} \mathrm{H}$ NMR spectra. Figure 4 shows the composition of the copolymers formed in the copolymerization at 70 and $80^{\circ} \mathrm{C}$ at different times, where the concentrations of DVA, AAc, and MAIB were 0.20, 0.50, and $0.60 \mathrm{~mol} / \mathrm{L}$, respectively (runs $8,12-21$ in Table I).

For the copolymers formed at $80^{\circ} \mathrm{C}$, the fraction (20-38 mol \%) of methoxycarbonylpropyl group derived from the initiator increased with time and leveled off over $6 \mathrm{~h}$. Thus, a large number of initiatorfragments were incorporated as terminal groups into the copolymers, indicating that an IFIRP proceeded 


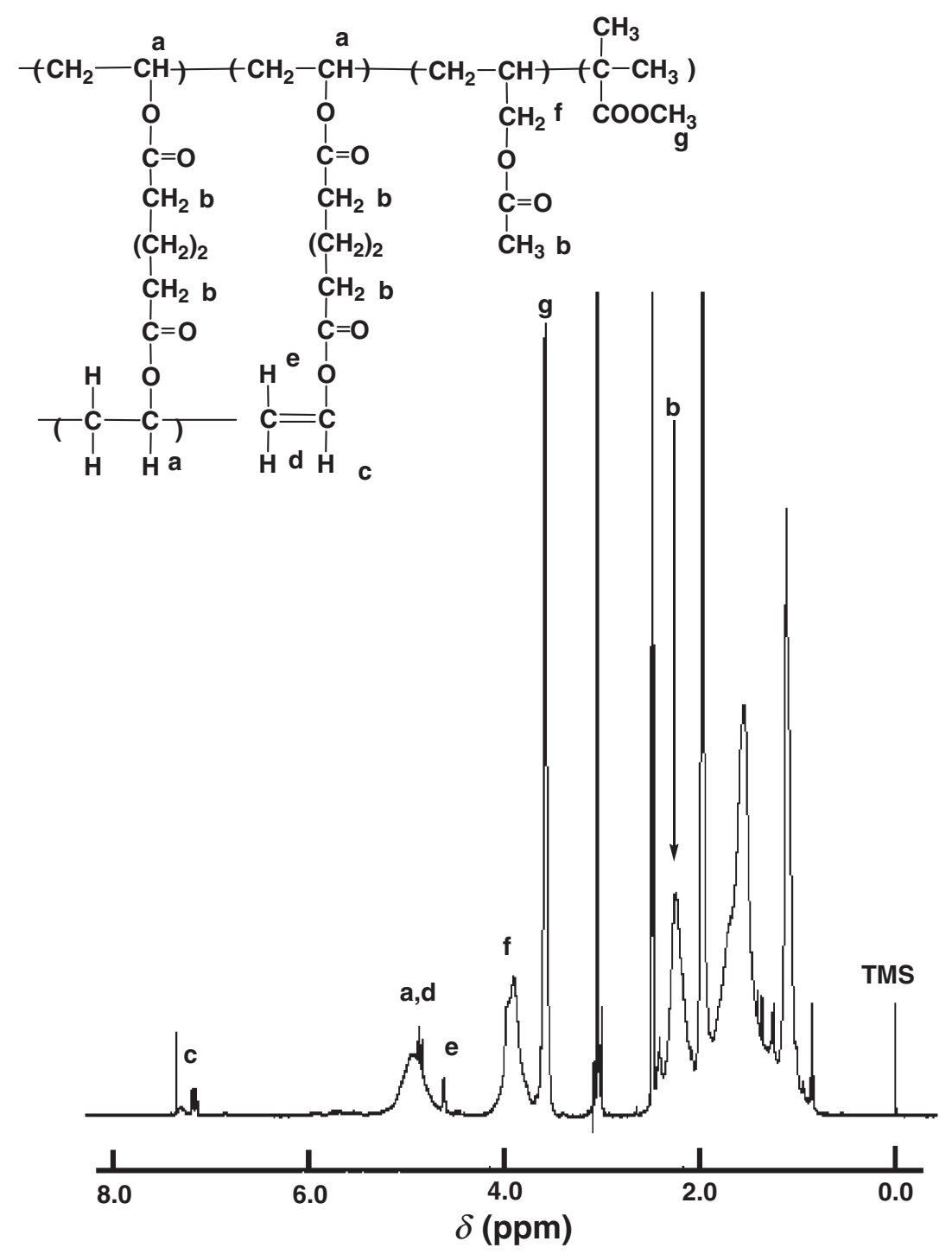

Figure 3. ${ }^{1} \mathrm{H}$ NMR spectrum of the copolymer formed in the copolymerization of DVA $(0.20 \mathrm{~mol} / \mathrm{L})$ and $\mathrm{AAc}(0.50 \mathrm{~mol} / \mathrm{L})$ with $\operatorname{MAIB}(0.60 \mathrm{~mol} / \mathrm{L})$ in benzene at $80^{\circ} \mathrm{C}$ for $4 \mathrm{~h}$.

in the present system to give hyperbranched copolymers. The content $(37-46 \mathrm{~mol} \%)$ of the AAc unit tended to decrease with time. The fraction (3-16 mol \%) of the DVA unit with a double bond reasonably decreased with time, while that (18-24 mol \%) of the DVA without a double bond somewhat increased with time. Similar results were also observed for the copolymers formed at $70^{\circ} \mathrm{C}$.

The number $(\mathrm{A})$ of branching points in a branched polymer is related to the number (B) of terminal groups by $\mathrm{A}=(\mathrm{B}-2)$. When the molecular weight of the polymer is enough high, A is nearly equal to B. If all of the terminal groups in the present copolymer are the methoxycarbonylpropyl group as MAIB-fragment, the $35 \mathrm{~mol} \%$ fraction of the incorporated initiator-fragment corresponds to the fact that the copolymer contains one branching point per 65/35 (=1.9) monomer units. A schematic structure of the resulting copolymer is shown in Scheme 1.

Owing to the lack of intermolecular entanglements, the solution viscosity of dendritic polymers such as dendrimers and hyperbranched polymers is well known to be very low. ${ }^{26-32}$ Viscometric measurements were performed at $25^{\circ} \mathrm{C}$ on benzene solutions of the copolymer formed in the copolymerization at $80^{\circ} \mathrm{C}$ for $4 \mathrm{~h}$, where the concentrations of DVA, AAc, and MAIB were $0.20,0.50$, and $0.60 \mathrm{~mol} / \mathrm{L}$ (run 8 in Table I). Figure 5 shows the relationship between reduced viscosity $\left(\eta_{\text {red }}\right)$ and polymer concentration (C). The very low $\eta_{\text {red }}$ values were observed, leading to an extremely low intrinsic viscosity $([\eta]=0.030 \mathrm{dL} / \mathrm{g})$.

Nanoparticles of 2-4 nm diameter were observed in a TEM image of the same copolymer (run 8 in Table I), though not clearly. The diameters well correspond to the $M_{\mathrm{w}}\left(1.5 \times 10^{4}\right)$ value of the copolymer. The hyperbranched copolymer molecules are expect- 


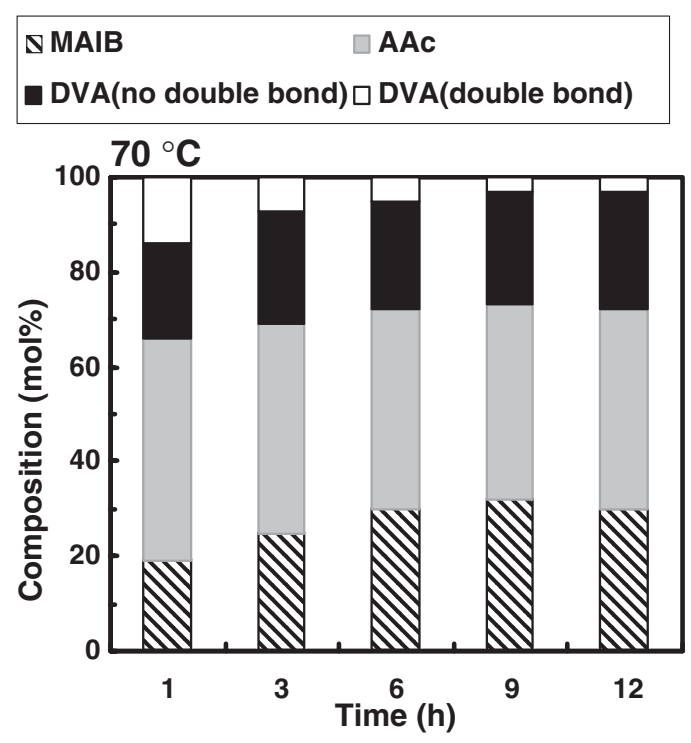

$80^{\circ} \mathrm{C}$

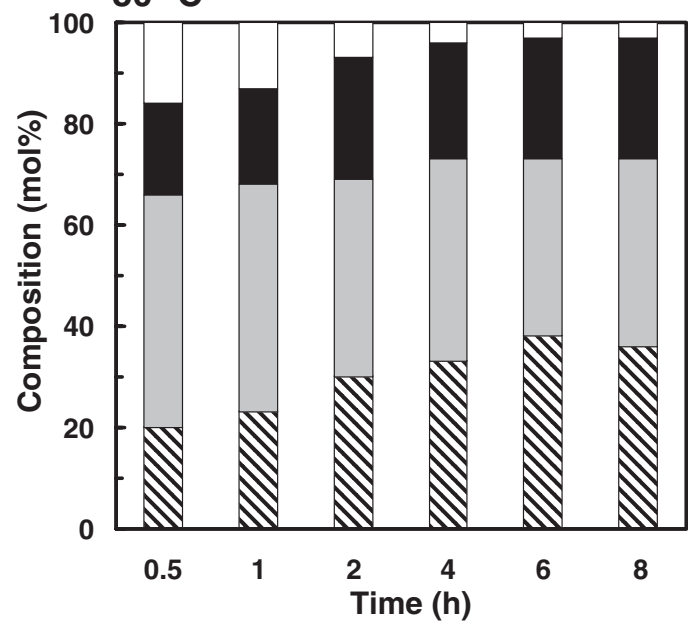

Figure 4. Composition of the copolymers formed in the copolymerization of DVA $(0.20 \mathrm{~mol} / \mathrm{L})$ and AAc $(0.50 \mathrm{~mol} / \mathrm{L})$ with MAIB $(0.60 \mathrm{~mol} / \mathrm{L})$ in benzene at 70 and $80^{\circ} \mathrm{C}$ at different times.

ed to be easily isolated as individual particles owing to their slight intermolecular interactions. So, the observed nanoparticles seems individual copolymer molecules.

Figure 6 shows TG and differential thermogravimetric (DTG) curves of the same copolymer. The thermal degradation of the copolymer began at $260^{\circ} \mathrm{C}$ and showed a maximal rate at $350^{\circ} \mathrm{C}$. The residue at $500^{\circ} \mathrm{C}$ was $14 \%$ of the initial polymer weight. The DSC curve of the copolymer showed an endothermic peak at $40^{\circ} \mathrm{C}$, probably corresponding to the glass transition temperature.

\section{Solubilization of Rhodamine $6 G$ as Dye Probe with the Resulting Copolymer}

Dendritic polymers were reported to show encapsulation and transport properties for organic or metalloorganic molecules such as dyes and metallo-porphy- rins owing to their void-containing structures. ${ }^{33-38}$ Such properties were examined on the copolymer formed in the copolymerization at $80^{\circ} \mathrm{C}$ for $4 \mathrm{~h}$ (run 8 in Table I) using Rhodamine 6G as a dye probe. The dye was soluble in water but was almost insoluble in toluene. The UV-vis spectra of the following two samples are compared in Figure 7. Sample (a): A toluene phase formed when $5 \mathrm{~mL}$ of a toluene solution containing the copolymer $(50 \mathrm{mg})$ was added to $2 \mathrm{~mL}$ of an aqueous solution Rhodamine 6G $(0.01 \mathrm{wt} \%)$, stirred for $1 \mathrm{~min}$, and then allowed to stand for $1 \mathrm{~d}$ [Spectrum (a)]. Sample (b): A toluene phase formed when $5 \mathrm{~mL}$ of toluene was added to $2 \mathrm{~mL}$ of the same aqueous dye solution and treated in the same manner as sample (a) [Spectrum (b)]. Thus, the toluene solution of the copolymer showed the absorption due to Rhodamine $6 \mathrm{G}$ at $430-580 \mathrm{~nm}$, while the toluene phase without the copolymer showed little absorption at $430-580 \mathrm{~nm}$. These results indicate that the hyperbranched copolymer can encapsulate and transfer the dye from the aqueous phase to the toluene phase.

\section{Stabilization of Metal Nanoparticles with the Result- ing Copolymer}

Dendritic polymers are well known to stabilize metal nanoparticles by encapsulating them in the void structures of the polymers. ${ }^{39-47}$ The hyperbranched copolymer formed in the present copolymerization (run 8 in Table I) was subjected to stabilization of nanoparticles of $\mathrm{Au}, \mathrm{Ag}$, and $\mathrm{Pd}$. Each metal salt was reduced with $\mathrm{NaBH}_{4}$ at room temperature in the presence of the copolymer, and then the metal particles-containing copolymer was isolated. Figure 8 shows UV-vis spectra of THF solutions of (a) Au and (b) Ag particles-containing copolymers $[0.25 \%$ (wt/ v)]. Thus, the reddish purple solution of the Au particles-containing copolymer exhibited an absorption at $523 \mathrm{~nm}$, and the yellowish brown one of the Ag particles-containing copolymer did an absorption at 414 $\mathrm{nm}$. These absorptions are due to the plasmon absorptions of the $\mathrm{Au}$ and $\mathrm{Ag}$ nanoparticles. ${ }^{39,41,44-47}$

Figure 9 presents TEM images of (a) $\mathrm{Au}$ and (b) Pd particles in the copolymer matrix prepared above. Au and Pd clusters were observed as nanoparticles of diameters of $10-15$ and $8-30 \mathrm{~nm}$, respectively.

These results indicate that the hyperbranched copolymer could stabilize nanoparticles of $\mathrm{Au}, \mathrm{Ag}$, and Pd. As stated above, the diameters of the copolymer particles were much smaller than those of the metal particles. Therefore, the metal particles were stabilized not by encapsulating in the inner voids of the hyperbranched copolymer ${ }^{40-43,47}$ but by attaching multiple hyperbranched copolymer molecules to one metal particle. $^{44-47}$ 

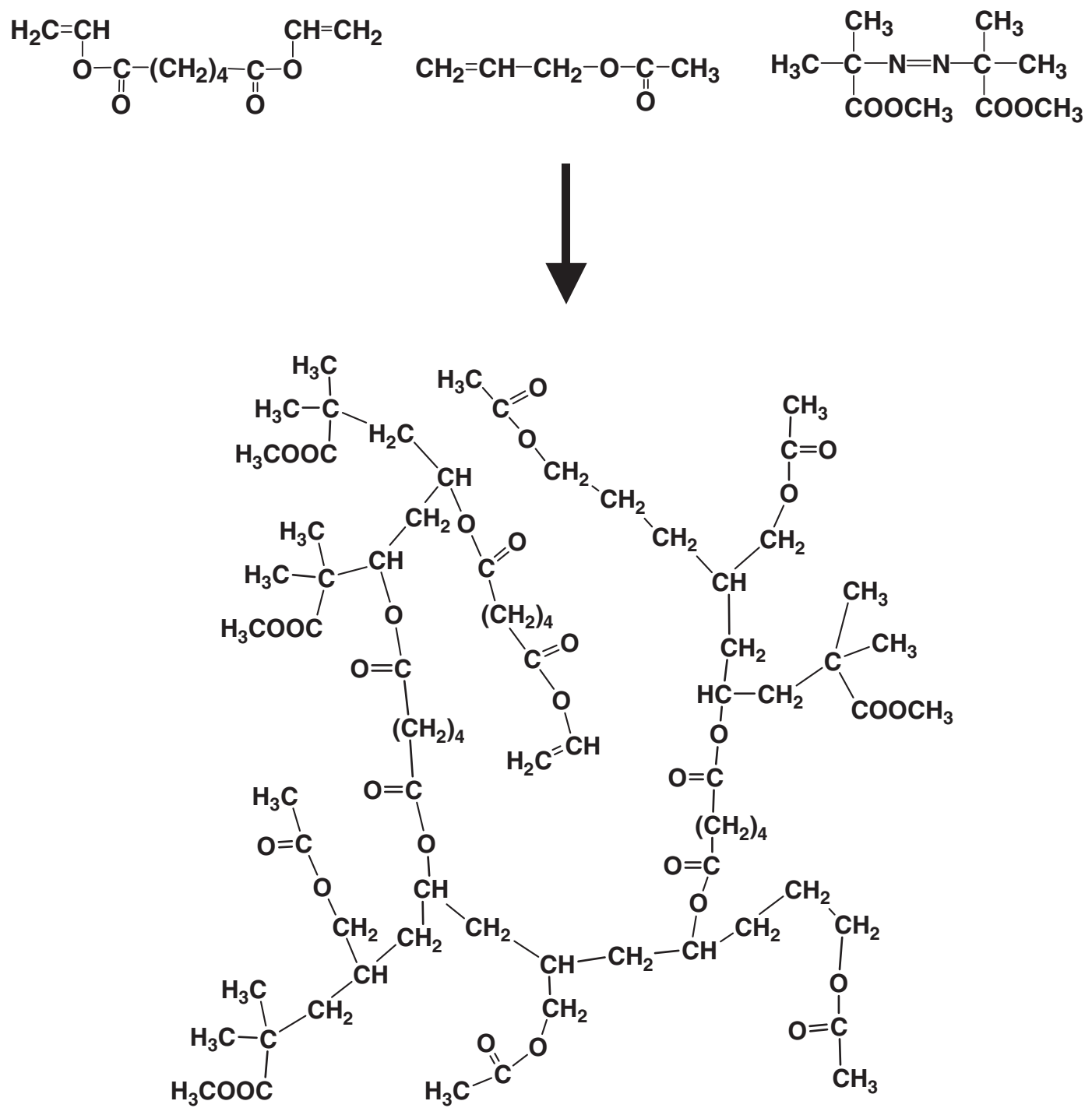

Scheme 1. Schematic structure of the hyperbranched copolymer.

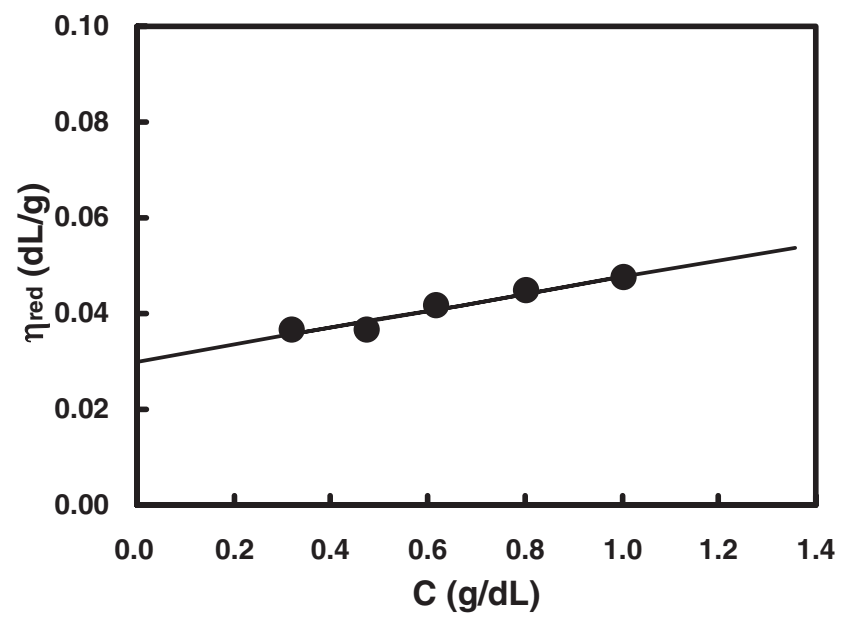

Figure 5. Relationship between the copolymer concentration (C) and $\eta_{\text {red }}$ in benzene at $25^{\circ} \mathrm{C}$. The copolymer was prepared by the copolymerization of DVA $(0.20 \mathrm{~mol} / \mathrm{L})$ and AAc $(0.50$ $\mathrm{mol} / \mathrm{L})$ with MAIB $(0.60 \mathrm{~mol} / \mathrm{L})$ in benzene at $80^{\circ} \mathrm{C}$ for $4 \mathrm{~h}$.

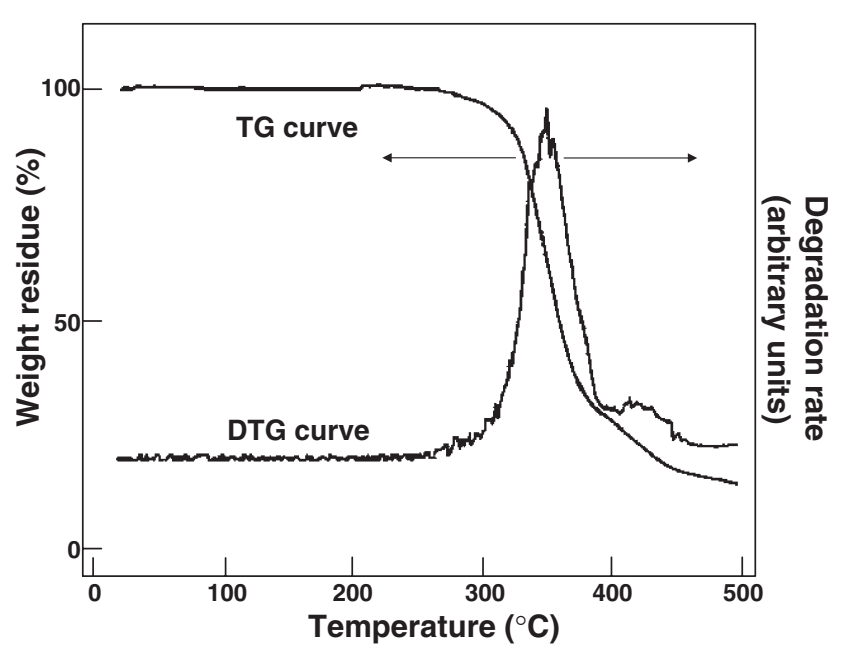

Figure 6. TG and DTG curves of the copolymer formed in the copolymerization of DVA $(0.20 \mathrm{~mol} / \mathrm{L})$ and AAc $(0.50 \mathrm{~mol} / \mathrm{L})$ with MAIB $(0.60 \mathrm{~mol} / \mathrm{L})$ in benzene at $80^{\circ} \mathrm{C}$ for $4 \mathrm{~h}$. 


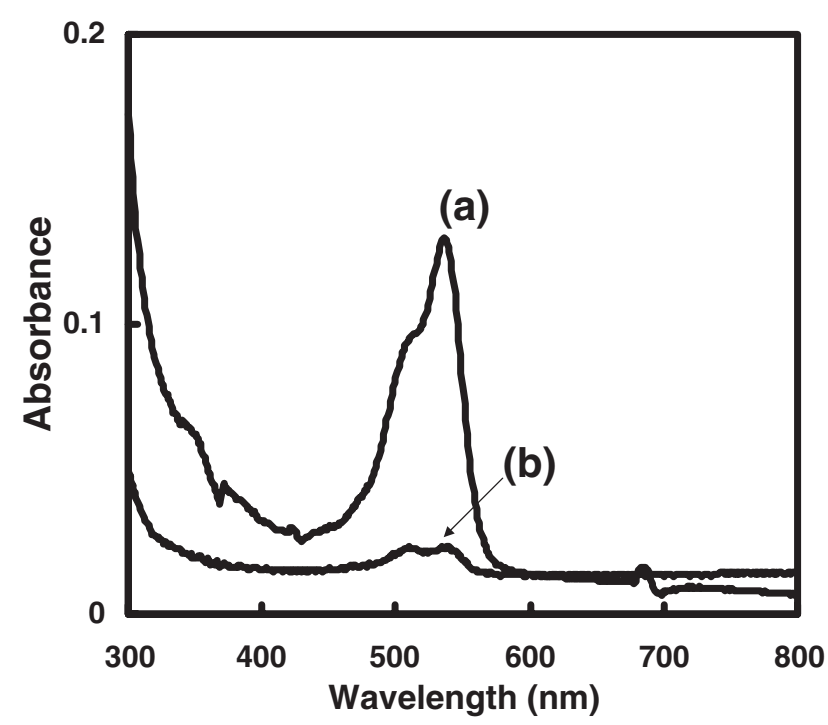

Figure 7. UV-vis spectra of toluene solutions $(5 \mathrm{~mL})$ containing (a) the copolymer $(50 \mathrm{mg}$ ) and (b) none in equilibrium with an aqueous Rhodamine $6 \mathrm{G}(0.01 \mathrm{wt} \%)$ solution $(2 \mathrm{~mL})$. The copolymer was prepared by the copolymerization of DVA $(0.20 \mathrm{~mol} / \mathrm{L})$ and AAc $(0.50 \mathrm{~mol} / \mathrm{L})$ with MAIB $(0.60 \mathrm{~mol} / \mathrm{L})$ in benzene at $80^{\circ} \mathrm{C}$ for $4 \mathrm{~h}$.
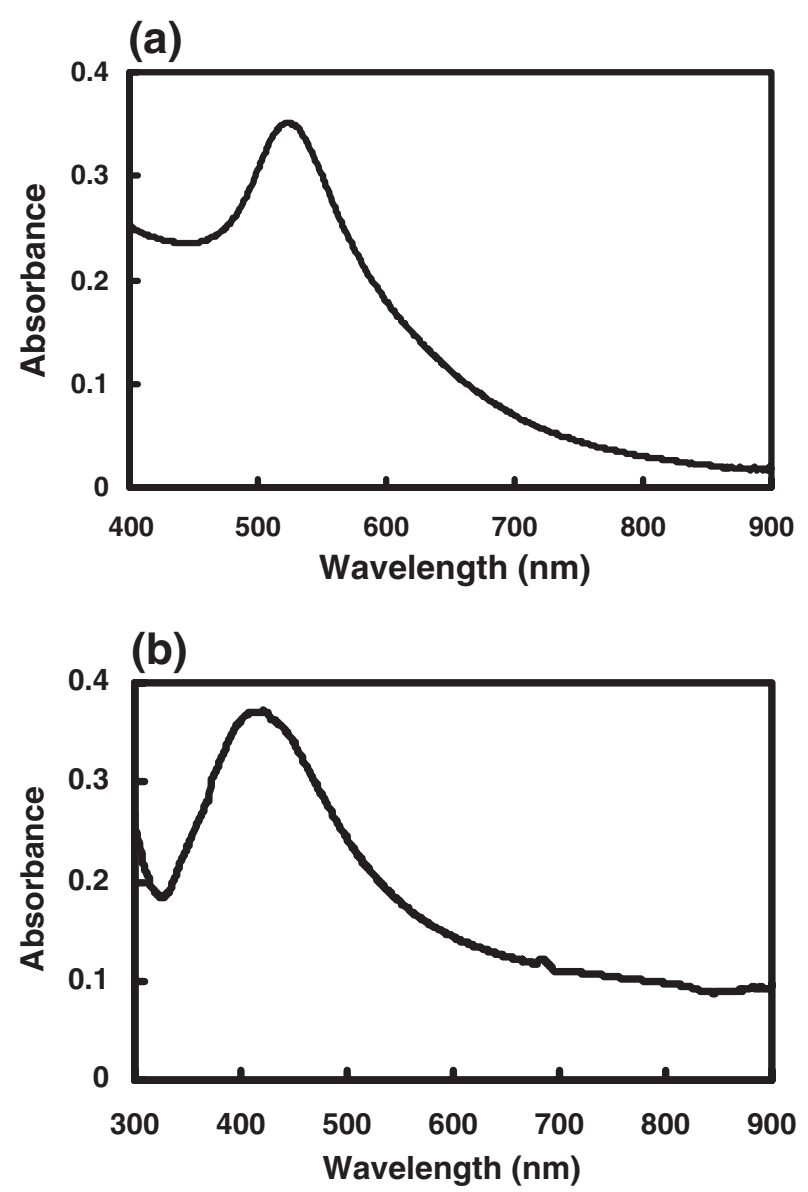

Figure 8. UV-vis spectra of THF solutions of (a) $\mathrm{Au}$ and (b) Ag particle-containing copolymers. (a)

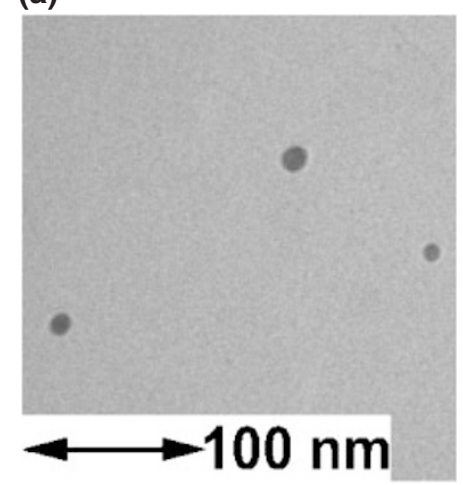

(b)

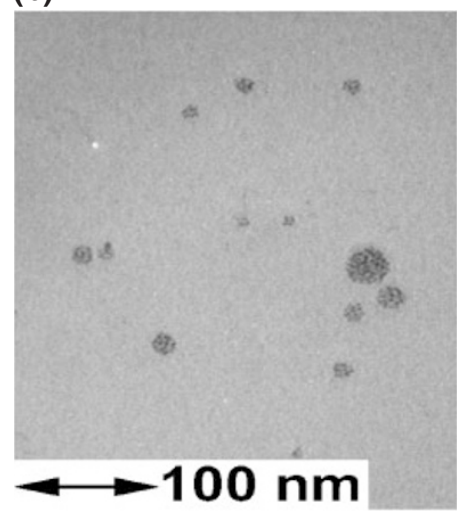

Figure 9. TEM images of (a) Au and (b) Pd particles in the copolymer matrix.

Formation of Porous Film from the Resulting Copolymer

An opaque film was formed by casting a copolymer solution in THF $(10 \mathrm{mg} / \mathrm{mL})$ on a glass slide. The copolymer used here was obtained in the copolymerization at $80^{\circ} \mathrm{C}$ for $4 \mathrm{~h}$ (run 8 in Table I). Figure 10 presents (a) optical microscope and (b) confocal scanning laser microscope images of the cast film. Thus, the film from the THF solution contained pores with polydisperse pore size $(5-15 \mu \mathrm{m})$.

Star, block, and comb polymers have been often observed to template around water droplets to form isoporous arrays when solutions of such polymers in a water-immiscible solvent such as chloroform, benzene, and carbon disulfide are cast onto a glass substrate and evaporated under a humidity atmosphere. After evaporation of solvent and water, the pores with regular structure and pore size are formed. In these cases, moisture is critical for the preparation of such porous polymer films. ${ }^{48-53}$

On the other hand, our porous film was formed by simply casting a polymer solution in THF as a water-miscible solvent onto a glass slide and drying in the atmosphere under no humidity conditions, although the pore size was considerably polydisperse and no regular array was observed. The humidity con- 
(a)

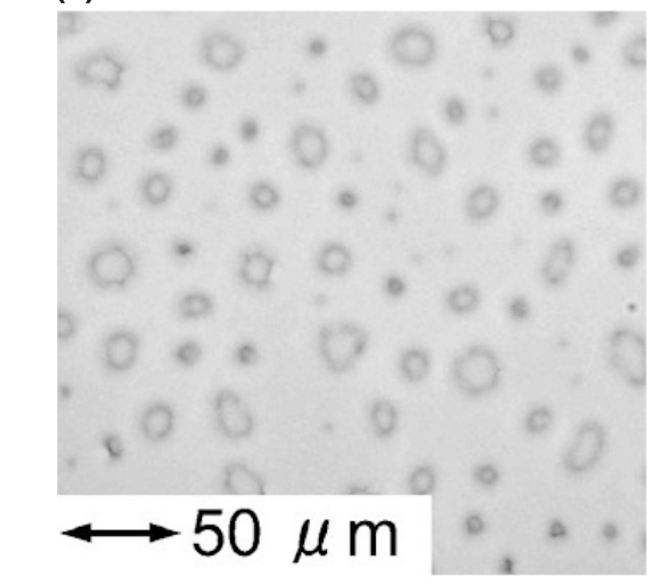

(b)

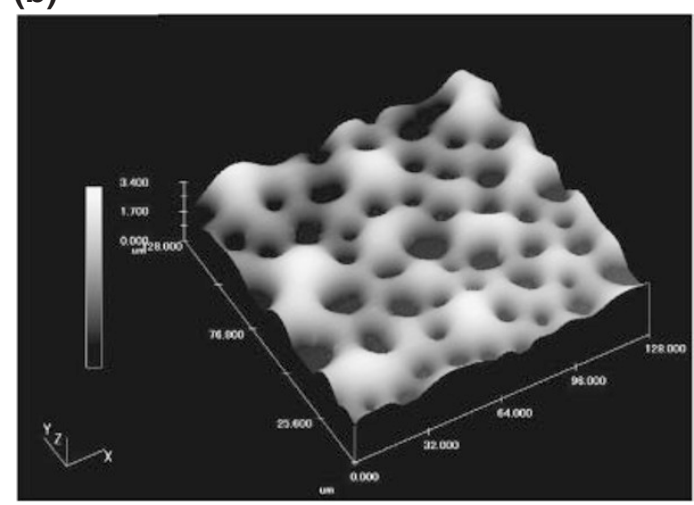

Figure 10. (a) Optical microscope and (b) confocal scanning laser microscope images of a porous film from a copolymer solution in THF $(10 \mathrm{mg} / \mathrm{mL})$.

ditions might be able to regulate the array and size of the pores. The formation of such a porous film seems characteristic of the hyperbranched polymers. A study on other hyperbranched polymers formed by IFIRP is in progress.

\section{CONCLUSIONS}

The copolymerization of DVA as an effective cross-linker with AAc as a degradative chain transfer reagent was examined at 70 and $80^{\circ} \mathrm{C}$ in benzene using MAIB of high concentrations. When the concentrations of DVA, AAc, and MAIB were 0.20, 0.50, and $0.60 \mathrm{~mol} / \mathrm{L}$, respectively, the copolymerization proceeded homogeneously with no gelation to yield soluble copolymer, while the use of higher DVA, lower AAc, or lower MAIB concentrations led to gelation. The soluble copolymer formed in the copolymerization at $80^{\circ} \mathrm{C}$ for $6 \mathrm{~h}$ consisted of the DVA units with $(3 \mathrm{~mol} \%)$ and without $(24 \mathrm{~mol} \%)$ double bond, the AAc unit $(35 \mathrm{~mol} \%)$, and the methoxycarbonylpropyl group (38 mol \%) as initiator-fragment, indicating that the copolymer is of a hyperbranched structure. The copolymer showed an upper critical solu- tion temperature $\left(38^{\circ} \mathrm{C}\right.$ on cooling) in a THF-water $[2: 1(\mathrm{v} / \mathrm{v})]$ mixture and exhibited the ability to solubilize Rhodamine $6 \mathrm{G}$ as a dye prove and stabilize metal $(\mathrm{Pd}, \mathrm{Au}$, and $\mathrm{Ag}$ ) nanoparticles. A porous film was obtained by simply casting a copolymer solution in THF.

Acknowledgment. The authors are grateful to the Center for Cooperative Research of Tokushima University for the NMR measurements and to Sanyo Chemical Industries, Ltd. for the TEM observation.

\section{REFERENCES}

1. Y. H. Kim, J. Polym. Sci., Part A: Polym. Chem., 36, 1685 (1998).

2. B. Void, J. Polym. Sci., Part A: Polym. Chem., 38, 2505 (2000).

3. M. Seiler, Chem. Eng. Technol., 25, 237 (2002).

4. A. Hult, M. Johansson, and E. Malmstroem, Adv. Polym. Sci., 143, 1 (1999).

5. B. Void, J. Polym. Sci., Part A: Polym. Chem., 43, 2679 (2005).

6. C. S. Hong, M. Jikei, and M. Kamimoto, Polym. J., 35, 586 (2003).

7. A. Morita, H. Kudo, and T. Nishikubo, Polym. J., 36, 413 (2004).

8. K. Yamamoto and M. Higuchi, Polym. J., 36, 577 (2004).

9. T. Sato, N. Sato, M. Seno, and T. Hirano, J. Polym. Sci., Part A: Polym. Chem., 41, 3038 (2003).

10. T. Sato, M. Hashimoto, M. Seno, and T. Hirano, Eur. Polym. J., 40, 273 (2004).

11. T. Sato, N. Higashida, T. Hirano, and M. Seno, J. Polym. Sci., Part A: Polym. Chem., 42, 1609 (2004).

12. T. Sato, Y. Arima, M. Seno, and T. Hirano, Polym. Int., 53, 1138 (2004).

13. T. Hirano, H. Ihara, T. Miyagi, M. Seno, and T. Sato, Macromol. Chem. Phys., 206, 860 (2005).

14. T. Sato, Y. Arima, M. Seno, and T. Hirano, Macromolecules, 38, 1627 (2005).

15. P. A. Costelleo, I. K. Martin, A. T. Slark, D. C. Sherrington, and A. Titterton, Polymer, 43, 245 (2002).

16. S. Graham, P. A. Cormack, and D. C. Sherrington, Macromolecules, 38, 86 (2005).

17. G. Odian, "Principles of Polymerization," 3rd ed., WileyInterscience, New York, 1991, p 521.

18. V. P. Zubov, M. V. Kumar, M. N. Masterova, and V. A. Kavanov, J. Macromol. Sci., Chem., A13, 111 (1979).

19. F. M. Lewis, C. Walling, W. Cummings, E. R. Briggs, and W. J. Wenisch, J. Am. Chem. Soc., 70, 1527 (1948).

20. K. Masaki, S. Ohkawara, T. Hirano, M. Seno, and T. Sato, J. Appl. Polym. Sci., 89, 2095 (2003).

21. H. S. Choi, T. Ooya, S. Sasaki, and N. Yui, Macromolecules, 36, 5342 (2003).

22. E. Djokpe and W. Vogt, Macromol. Chem. Phys., 202, 750 (2001).

23. S. Habaue, Y. Isobe, and Y. Okamoto, Tetrahedron, 58, 8205 (2002).

24. Y. Maeda, T. Nakamura, and I. Ikeda, Macromolecules, 34, 
8246 (2001).

25. G. Zhang, Macromolecules, 37, 6553 (2004).

26. K. Ishizu and A. Mori, Macromol. Rapid Commun., 21, 665 (2000).

27. A. K. Anderepoulou and J. K. Kallitsis, Macromolecules, 35, 5808 (2002).

28. H. Mori, D. C. Seng, H. Lechner, M. Zhang, and A. H. E. Mueller, Macromolecules, 35, 9270 (2002).

29. K. Xu, K. Peng, Q. Sun, Y. Dong, F. Salhi, J. Luo, Y. Huang, D. Zhang, Z. Xu, and B. Tang, Macromolecules, 35, 5821 (2002).

30. M. Jikei, R. Mori, S. Kawauchi, M. Kakimoto, and Y. Taniguchi, Polym. J., 34, 550 (2002).

31. B. Leoittenvin, R. Matmour, R. Francis, D. Taton, and Y. Gnanou, Macromolecules, 38, 3120 (2005).

32. S. Muthukrishnan, H. Mori, and A. H. E. Mueller, Macromolecules, 38, 3108 (2005).

33. A. Sander, M. Kraemer, R. Hanselmann, R. Muelhaupt, and H. Frey, Angew. Chem., Int. Ed., 38, 3552 (1999).

34. S.-E. Stiriba, H. Kautz, and H. Frey, J. Am. Chem. Soc., 124, 9698 (2002).

35. M. Schappacher and A. Deffieux, Polymer, 45, 4633 (2004).

36. C. R. Yates and W. Hayes, Eur. Polym. J., 40, 1257 (2004).

37. C. Gao and D. Yan, Prog. Polym. Sci., 29, 183 (2004).

38. S. Santra and A. Kumar, Chem. Commun., 2126 (2004).

39. A. Manna, T. Imae, K. Aoi, M. Okada, and T. Yogo, Chem. Mater., 13, 1674 (2001).

40. F. Groehn, X. Gu, H. Gruell, J. C. Meredith, G. Nisato, B. J. Bauer, A. Karim, and E. J. Amis, Macromolecules, 35, 4852
(2002).

41. C. Bao, M. Jin, R. Lu, T. Zheng, and Y. Zhao, Mater. Chem. Phys., 82, 812 (2003).

42. D. Tabuani, O. Monticelli, H. Komber, and S. Russo, Macromol. Chem. Phys., 204, 1576 (2003).

43. R. W. J. Scott, H. Ye, R. R. Henriquez, and R. M. Crooks, Chem. Mater., 15, 3873 (2003).

44. X. Sun, X. Jiang, S. Dong, and E. Wang, Macromol. Rapid Commun., 24, 1024 (2003).

45. X. Sun, S. Dong, and E. Wang, Macromolecules, 37, 7105 (2004).

46. N. Perignon, A.-F. Mingotaud, J.-D. Marty, I. Rico-Lattes, and C. Mingotaud, Chem. Mater., 16, 4856 (2004).

47. V. M. Garamus, T. Maksimova, W. Richtering, C. Aymonier, R. Thomann, L. Antoniette, and S. Mecking, Maromolecules, 37, 7893 (2004).

48. M. H. Stenzel-Rosenbaum, T. P. Davis, A. G. Fane, and V. Chen, Angew. Chem., Int. Ed., 40, 3428 (2001).

49. L. A. Connal, P. A. Gurr, G. G. Qiao, and D. H. Solomon, J. Mater. Chem., 15, 1286 (2005).

50. C. Barner-Kowollik, T. P. Davis, J. P. A. Heuta, M. H. Stenzel, P. Vana, and M. Whittaker, J. Polym. Sci., Part A: Polym. Chem., 41, 365 (2003).

51. M. Jesberger, L. Barner, M. H. Stenzel, E. Malmstroem, T. P. Davis, and C. Barner-Kowollik, J. Polym. Sci., Part A: Polym. Chem., 41, 3847 (2003).

52. Y. Maeda, Y. Shimoi, and K. Ogino, Polym. Bull., 53, 315 (2005).

53. H. Yabu and M. Shimomura, Langmuir, 21, 1709 (2005). 